\title{
SISTEM PEMBUATAN BARCODE BARANG BERBASIS WEB PADA PT. CHUGOKU PAINTS INDONESIA
}

\author{
Ilamsyah $^{1}$ \\ Dona Listyanto Pangestu ${ }^{2}$ \\ Reza zulian Pramana ${ }^{3}$
}

\begin{abstract}
Dosen Tetap STMIK Raharja ${ }^{1}$, Mahasiswa STMIK RAHARJA Jurursan Teknik Informatika ${ }^{2,3}$ Jl. Jendral Sudirman No 40, Modernland Tangerang ${ }^{1,2,3}$ email:ilamsyah@raharja.info ${ }^{1}$,dona.listyanto@raharja.info ${ }^{2}$,rezazulianpramana@raharja.info ${ }^{3}$
\end{abstract}

\begin{abstract}
ABSTRAKSI
PT.CHUGOKU PAINTS INDONESIA adalah sebuah perusahaan swasta yang bergerak di bidang jasa pembuatan cat untuk kebutuhan industri dengan kualitas dan formulasi dari jepang. Perusahaan yang memproduksi berbagai macam jenis cat untuk pabrik. Mulai dari pembuatan cat khusus kapal ,pembangkit listrik , baja dan kayu untuk memenuhi kebutuhan costumer dibidang industri.dimana perusahaan ini. Masih dilakunnya proses pembuatan barcode yang masih manual dan belum terintegrasi dengan suatu web sehinga dapat mempermudah pembuatan dan pengontrolan dalam pembuatan barcode barang. Perkembangan teknologi pada system komputer memungkinkan perbaikan di segala biadang produksi, seperti proses pembuatan barcode barang masih manual, proses pembuatan barcode tersebut menjadi lambat dan tergantung kondisi. Karena dengan adanya system pembuatan barcode yang telah menggunakan web akan membawa suatu kemudahan untuk perusahaan tersebut untuk dapat beraktifitas dengan mudah. Penggunaan sistem komputer sangat penting dalam menunjang sebuah perkembangan perusahaan dalam saat ini. Penggunaan komputer juga dapat mempermudah dan memperlancar dalam proses pengolahan, penyimpanan data yang penting bahkan sebagai bahan perusahaan itu sendiri. Metodologi yang digunakan adalah metode penelitian yang di mulai dengan melakukan survey, wawancara, dan analisis sesuai teori pada buku-buku yang dapat mendukung perancangan pembuatan barcode barang. Dari hasil penelitian ini, PT. CHUGOKU PAINTS INDONESIA dapat meningkatkan produtivitas dan kinerja dalam perusahaan untuk dapat bersaing dalam dunia bisnis yang semakin ketat. Selain itu, dengan penelitian ini perusahaan memiliki kemampuan yang lebih baik untuk saat ini maupun yang akan datang.
\end{abstract}

Kata kunci: sistem komputer, barcode dan web

\section{ABSTRACT}

PT.CHUGOKU PAINTS INDONESIA is a private company engaged in the manufacture of paints for industrial needs with the quality and formulation of Japan. A company that produces various types of paint for the plant. Ranging from the manufacture of special paint ships, power plants, steel and wood to meet customer needs in the field of industri.di where this company. Still barcode creation process is still manual and not integrated with a web so that it can facilitate the manufacture and control in the manufacture of barcode goods. Technological developments in the computer system enables improvement in all branches of production, such as the manufacture of goods still manual barcode, barcode creation process is slow and depends on the conditions. Due 
to the manufacture of barcode system that has been using the web will bring an ease to the company to be able to indulge easily. The use of computer systems is very important in supporting a company's development in today. Computer use can also facilitate and expedite the processing, storing important data even as the company's own material. The methodology used is a method of research that began by conducting surveys, interviews, and analysis according to the theory of the books that can support the design manufacture goods barcode. From these results, PT. CHUGOKU PAINTS INDONESIA can improve produtivitas and performance of the company to be competitive in the business world that is increasingly tight. In addition, with this research the company has a better ability to present and future.

Keywords: computer systems, barcode and web

\section{PENDAHULUAN}

Perkembangan dunia teknologi saat ini semakin cepat memasuki berbagai bidang dan kini menjadi kebutuhan sehari hari untuk kepentingan pribadi, sekolah, maupun perusahaan. Sehingga kini semakin banyak Perusahaan yang berusaha meningkatkan usahanya terutama dalam bisnis yang sangat berkaitan erat dengan teknologi itu sendiri. Komputer merupakan suatu alat penghitung dan juga dapat sebagai alat efisiensi kerja yang berguna menghasilkan suatu informasi dengan cepat, tepat dan akurat sehingga teknologi komputer ini menjadi kebutuhan yang mendasar dan tidak dapat dipisahkan dalam membantu sistem yang dibutuhkan.

Perusahaan-perusahaan yang ingin mengembangkan usaha dan mencapai sukses harus mengikuti era informasi dengan menggunakan suatu sistem komputer. Dengan adanya komputer sebagai alat pengolah data, maka semua bidang dalam suatu perusahaan ataupun instansi dapat dimaksimalkan kinerjanya, dalam hal ini bidang-bidang yang dianggap penting dan utama karena hal ini dapat mendukung keberhasilan suatu perusahaan dalam mencapai tujuannya. PT.CHUGOKU PAINTS INDONESIA merupakan Perusahaan pembuat cat untuk kebutuhan industri dengan kualitas dan formulasi dari jepang.

Pada Perusahaan ini terdapat suatu sistem pembuatan barcode barang yang masih berjalan secara manual, dimana dalam penerapan sistem ini terdapat beberapa hal yang menjadi kendala, yaitu diantaranya adalah keefektifan dan efisiensi proses pembuatan barcode,pembuatan barcode masih di lakukan secara manual mengunakan sebuah software dan belum terintegrasi dengan web sehingga menjadi tidak efektif. Dikarenakan Perusahaan ini memiliki kekurangan dalam pembuatan barcode barang yang masih manual dan belum terintegrasi dengan web.

\section{METODE PENELITIAN}

Masalah yang sering dihadapi adalah dimana masalah yang timbul pada saat pembuatan barcode masih di lakukan secara manual dan masih menggunakan sebuah software dan masih belum terkonfigurasi dengan sebuah web sehingga sering terjadinya kesalahan dalam pencetakan barcode tersebut. Oleh karena itu, dengan adanya masalah yang sering terjadi ini dibuatlah system berbasis web dalam pembuatan barcode di PT.CHUGOKU 
PAINTS INDONESIA yang masih manual saat ini.Dengan adanya system berbasis web ini dapat mempermudah pekerjaan dan penginputan pembuatan barcode barang agar hal-hal yang tidak diinginkan tidak terjadi kesalahan.

\section{A. Metode Pengumpulan Data}

Ada beberapa pengumpulan data. Suatu pengumpulan data di lakukan dengan metode tertentu sesuai dengan tujuannya. Ada berbgai metode antara lain : wawancara observasi dan wawancara kuesioner

Metode yang di pilih untuk setiap variable tergantung pada berbagai factor terutama jenis data dan ciri data responden. Untuk data responden untuk data historis misalnya tidak bisa di temukan dengan observasi tapi di mungkinkan dengan wawancara . hal ini tergantung dari karakteristik data variable, maka metode yang digunakan tidak selalu sama untuk setiap variable.

\section{B. Metode Penelitian}

- Metode pengumpulan data dengan cara mengamati langsung masalah yang ada pada saat observasi. Pada sistem pembuatan barcode barang di PT.CHUGOKU PAINTS INDONESIA

- Mempelajari prosedur - prosedur oprasional yang berlaku pada PT. CHUGOKU PAINTS INDONESIA terkait dengan proses pembuatan barcode barang

- Meninjau kekurangan dan kelemahan system yang sedang berjalan. Apakah system yang berjalan sudah optimal dan mendukung efesiensi kinerja bagian packing
- Membuat rancangan system untuk PT. CHUGOKU PAINTS INDONESIA, yang selanjutnya akan digunakan untuk untuk merancang sebuah system pembuatan barcode barang berbasis web

\section{LITERATURE RIVIEW}

Banyak penelitian yang di lakukan sebelumnya dalam pembuatan barcode barang. Agar pengembangan system ini dapat di lakukan dengan optimal. Sehingga menghindari pembuatan ulang dan mengidentifikasi suatu metode penelitian yang pernah dilakukan sebelumnya. Mengetahui orang lain yang memiliki sepesialisasi penelitian yang sama di bidang ini. Beberapa Literature riview tersebut adalah sebagai berikut :

1. Penelitian yang dilakukan oleh Happy Chandraleka Universitas Diponegoro (2013). Penelitian yang dilakukan oleh Happy Chandraleka. mengenai sistem Barcode dan QR code permasalahan yang terjadi pada judul yang diangkat penulis adalah agar dapat memberikan penjelasan tentang apa pengertian dan fungsi dari barcode tersebut

2. Penelitian yang dilakukan oleh Ir.Sere Saghranie Daulay,M.SI Widyaiswara Madya Pusdiklat Industri (2011). Penelitian yang dilakukan oleh Ir.Sere Saghranie Daulay,M.SI mengenai Hubungan Barcode dengan Produk Industri Sebagai Standar Perdagangan Produk Industri Masa Kini pada judul yang diangkat penulis adalah agar mengetahui gambaran suatu barcode serta kegunaanya dalam dunia industri masa kini

3. Penelitian yang dilakukan oleh Restu Buana Kusuma Sakti Nugraha Universitas Diponegoro (2010). Penelitian yang 
dilakukan oleh Restu Buana Kusuma Sakti Nugraha Universitas Diponegoro pada judul yang diangkat penulis adalah agar dapat bertujuan sebagai informasi tentang data barang dan pembuatan barcode maka dari itu penulis perlu di lakukan penelitian software aplikasi barcode pada proses monitoring barang dengan pemrograman borlan delphi

4. Penelitian yang dilakukan oleh Untung Raharja ,Dina Fitri Murad,Siti Amanih Jurnal CCIT (2006). Penelitian yang dilakukan oleh Untung Raharja ,Dina Fitri Murad,Siti Amanih Jurnal CCIT pada judul yang diangkat penulis adalah Konsep Sistem Pengkodean Baris (BARCODE) Sebagai Solusi Efesiensi Waktu Dan Biaya. Dimana sistem pengkodean barang masihn dilakukan secara manual pada suatu perusahaan kecil dan menengah sehingga menyebabkan pekerjaan tidak efesien dan seringkali perusahaan yang ingin menerapkan sistem barcode terbentur dengan tingginya biaya yang di timbulkan .Untuk membuat barcode harus adanya suatu software yang di khususkan

5. penelitian yang di lakukan oleh hazim umam sekolah tinggi teknolog indonesia tanjung pinang (2013). STNK terbuat dari kertas dan ukurannya tidak fleksibel yakni $7 \frac{1}{2} \mathrm{~cm} \times 22 \frac{1}{2} \mathrm{~cm}$. Sehingga menyulitkan pemilik dalam menyimpan STNKnya.Tidak ada aturan resmi untuk membawa STNK, apakah harus dilipat (sehinggamenjadi separuh ukuran aslinya) atau tidak. Karena terbuat dari kertas, STNKsangat rentan terhadap kerusakan fisik dan juga menyebabkan pemborosan kertas. Dengan adanya perasalahan yang terjadi di lapangan, penulis tertarik untuk membangun sebuah sistem yang mampu mempermudah para petugas polisi LANTAS (Lalu Lintas) maupun SAMSAT dalam memverifikasi STNK

\section{PEMBAHASAN}

A. Use Case Diagram Sistem Pembuatan Barcode Barang

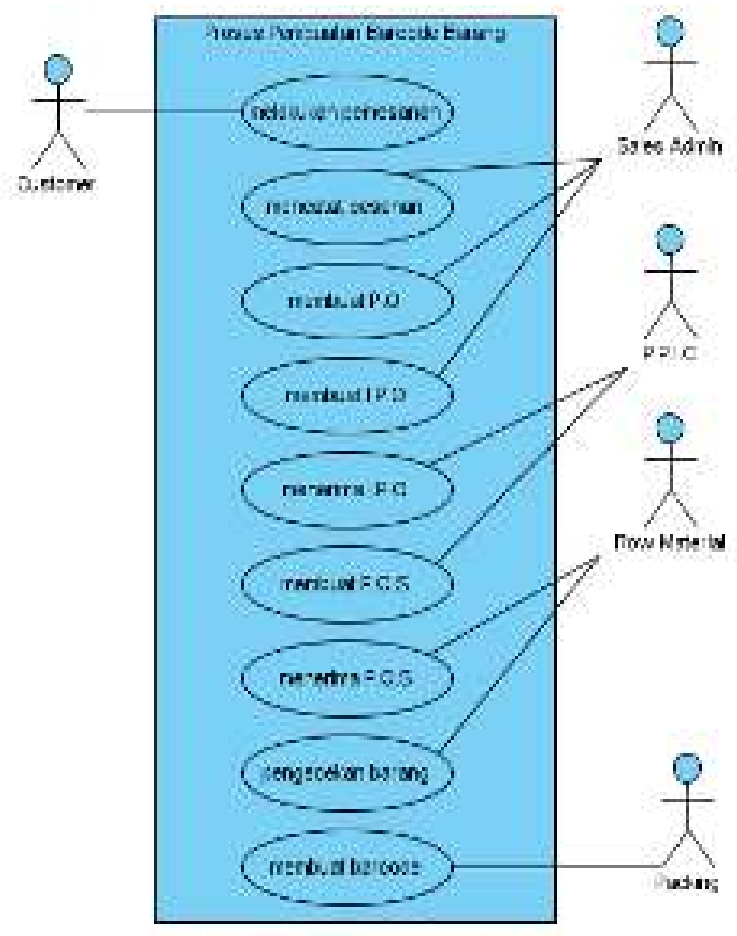

\section{Gambar 1. Use Case Diagram Sistem Pembuatan Barcode Barang}

Dari hasil penelitian dapat di jelaskan dalam bentuk Use Case Diagram. Dimana di gambarkan apa saja yang dilakukan Customer melakukan pemesanan barang dan bagian sales admin mencatat pesanan dan membuatkan P.O (Purchase Order) Setelah itu bagian sales admin membuatkan I.P.O (Internal Purchase Order) lalu Bagian PPIC menerima I.P.O (Internal Purchase Order) lalu membuat P.O.S (Production Order Shit) kemudian Bagian Row Material menerima P.O.S (Production Order Shit) dan melakukan proses pengecekan barang Setelah melakukan pengecekan barang, lalu 
di buatkan barcode pada bagian packing barang.

\section{B. Activity Diagram Pembuatan Barcode Barang}

Activity diagram memodelkan alur kerja sebuah proses dan urutan aktivitas pada suatu proses. Diagram ini sangat mirip dengan Flowchart digunakan untuk menggambarkan alur kerja dari sebuah sistem, sedangkan activity diagram dibuat untuk menggambarkan aktivitas dari aktor.Berdasarkan dari use case diatas, dapat kita gambarkan Activity diagram dari aktivitas para aktor-aktor yang ada pada pembuatan barcode barang

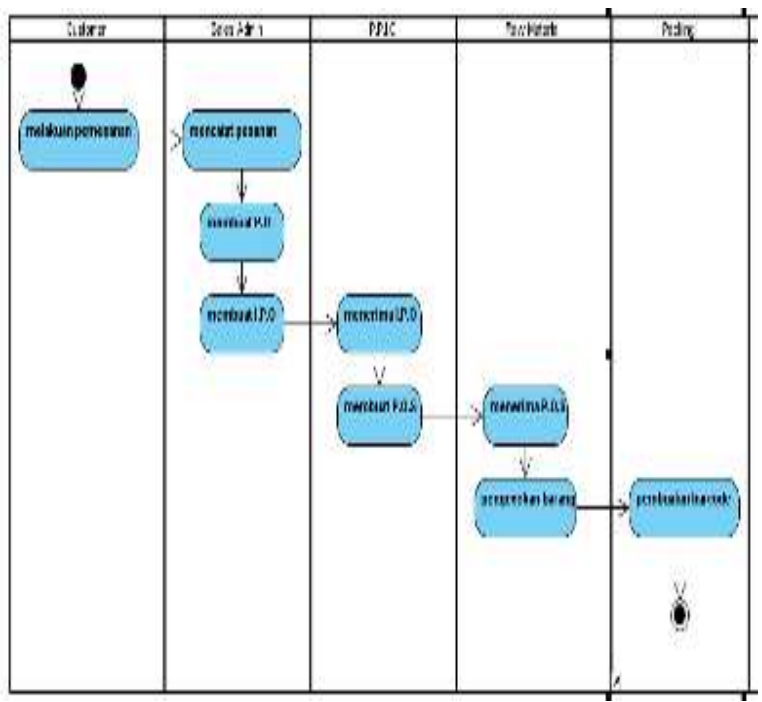

Gambar 2. Activity Diagram Sistem Pembuatan Barcode Barang

C. Squence Diagram Sistem Pembuatan Barcode Barang

Sequence diagram menggambarkan interaksi antar objek di dalam dan di sekitar sistem (termasuk pengguna display, dan sebagainya) berupa message yang digambarkan terhadap waktu. Sequence diagram terdiri atas dimensi vertical (waktu) dan dimensi horizontal (Objek-objek yang terkait). Sequence diagrambiasa digunakan untuk menggambarkan scenario atau rangkaian langkah-langkah yang dilakukan sebagai respon dari sebuah event untuk menghasilkan output tertentu. Diawali dari apa yang akan dimulai dari aktivitas tersebut, proses dan perubahan secara internal dan output apa yang dihasilkan.

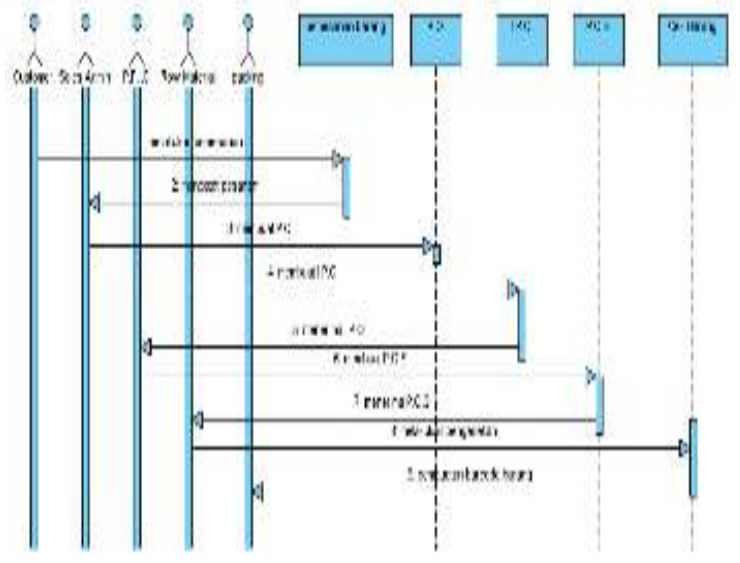

\section{Gambar 3. Squence Diagram Sistem Pembuatan Barcode Barang}

\section{IMPLEMENTASI}

Rancangan tampilan berbasis web. Rancangan ini di buat dengan menggunakan Macromedia Dreamweaver dan program php. Merancang aplikasi dengan menggunakan program open source (PHP) dan dapat lebih mudah dalam pengembangannya karena bejalan di semua platform.

Berikut ini adalah tampilan system pembutan barcode barang 


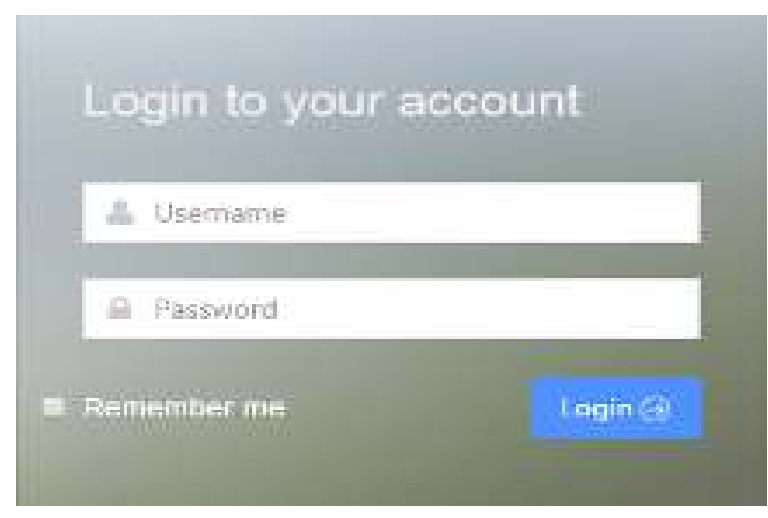

Gambar 4. Tampilan Login

Setelah user sudah melakukan login maka akan di tampilkan menu utama dari system pembuatan barcode barang seperti gambar 5 dibawah ini
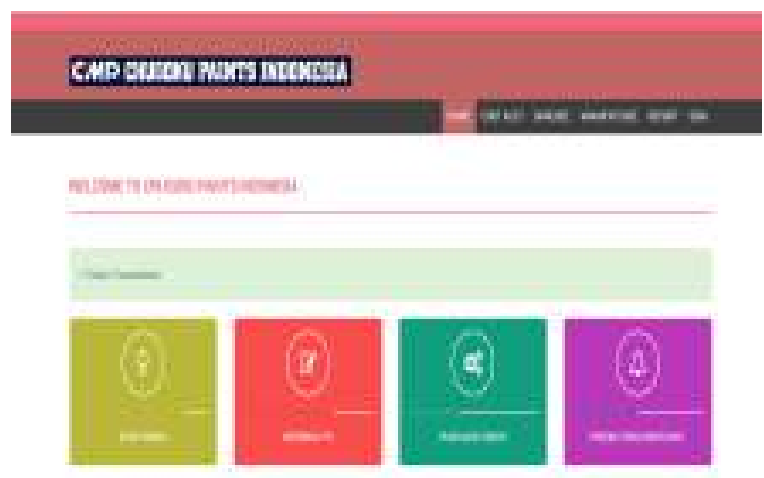

Gambar 5. Tampilan Menu Utama

Berikut ini ada beberapa tampilan sebagai dari menu system pembuatan barcode barang secara menyeluruh

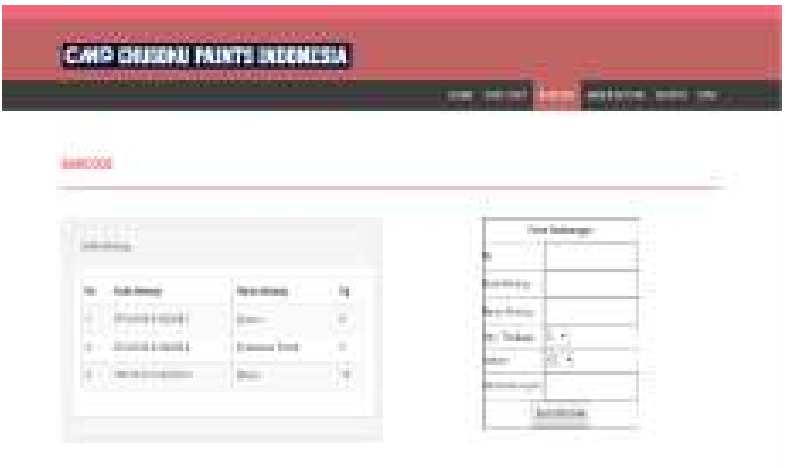

Gambar 6. Tampilan Menu Pembuatan Barcode

Pada tampilan ini menampilkan pembuatan barcode barang dimana menampilkan table daftar barang yang akan di buatkan barcode dan juga terdapat tampilan pembuatan barcode

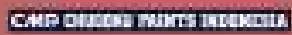

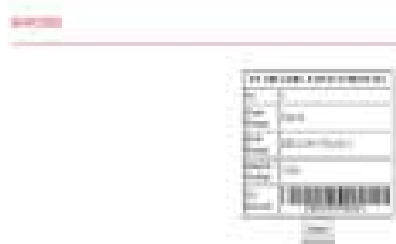

\section{Gambar 6. Tampilan Menu Pembuatan} Barcode

Pada tampilan ini menampilkan hasil dari pembuatan barcode barang yang tadi sudah di inputkan pada tampilan sebelumnya, dan juga terdapat tombol print

\section{KESIMPULAN}

Sistem pembuatan barcode barang yang diterapkan di PT. CHUGOKU PAINTS 
INDONESIA belum cukup maksimal karena masih dilakukan dengan cara manual sehingga membutuhkan waktu yang cukup lama untuk menyelesaikanya . Maka dari itu di buatkanlah system pembuatan barcode yang terintegrasi dengan web, untuk mengurangi kesalahan dalam penginputan dan pembuatan barcode barang Sistem pembuatan barcode yang sekarang ini berjalan ini berjalan pada PT. CHUGOKU PAINTS INDONESIA belum terintegrasi web sehingga masih kurang efektif dan efisien.

\section{DAFTAR PUSTAKA}

1. Arief, M. Rudyanto. 2011. "Pemrograman Web Dinamis Mengunakan PHP dan MySQL". Yogyakarta: Andi.

2. Community, eWolf. 2012. "Panduan Internet Paling Gampang".Yogyakarta: Cakrawala Css.

3. Happy Chandraleka Universitas "Sistem Barcode dan QR code". Diakses pada tanggal 12 desember 2015 dari http://ilmukomputer.org/wpcontent/uploads/2013/11/hchandralekamenyingkap-barcode-qrcode.doc.

4. Hazim Umam " Sistem Vertivikasi STNK Mengunakan Barcode di Kator Samsat Tanjung Pinang" Diakses pada tanggal 12 desember http://180.242.93.57/ digilib/download. php?id=826.

5. Herlawati, Widodo, Prabowo Pudja. 2011 "Menggunakan UML". Bandung: Informatika Pengunaan UML.

6. Ir.Sere Saghranie Daulay,M.SI "Hubungan Barcode dengan Produk Industri Sebagai Standar Perdagangan Produk Industri Masa Kini”. Diakses pada tanggal 12 desember 2015 dari http://www.kemenperin.go.id/download
/6760/Hubungan-BARCODE-dengan-

Produk-Industri-Sebagai-Standar-

Perdagangan-Produk-Industri-Masa-

Kini.

7. Kadir, Abdul. 2010. "Membuat Aplikasi Web dengan HP dan Database MySQL". Yogyakarta: Andi Offset.

8. Khafidli, M. Firgiawan. 2011. "Trik Menguasai HTML5 CSS3 PHP Aplikatif. Yogyakarta: Lokomedia.

9. Kustiyahningsih,Yeni. 2011. "Pemrograman Basis Data Berbasis Web Menggunakan PHP \& MySQL". Jakarta: Graha Ilmu.

10. Restu Buana Kusuma Sakti Nugraha "tentang data barang dan pembuatan barcode". Diakses pada tanggal 12 desember 2015 http://eprints.undip.ac.id/4966/

11. Sibero, Alexsander F.K. 2012 "Kitab Suci Web Programing”. Jakarta: Mediakom.

12. Untung Raharja, Dina Fitri Murad,Siti Amanih Jurnal CCIT "Konsep Sistem Pengkodean Baris (BARCODE) Sebagai Solusi Efesiensi Waktu Dan Biaya". Jurnal CCIT 